\title{
Effectiveness of Structured Teaching Programme on Knowledge Regarding Prevention of Osteoporosis among Premenopausal Women
}

\author{
Solomon James Mangalaraj ${ }^{1}$, Sapna Yadav ${ }^{2}$, Shaloo Rathi ${ }^{3}$, Silpa Antony ${ }^{4}$, \\ Sonali Sharma ${ }^{5}$
}

${ }^{1} \mathrm{PhD}$ Nursing, Faculty, College of Nursing, AIIMS RAIPUR

${ }^{2-5}$ B.Sc. (Hons.) Nursing, College of Nursing, AIIMS RAIPUR

Corresponding Author: Solomon James Mangalaraj

\begin{abstract}
Osteoporosis, which means "porous bone", is a disease in which the bones gradually become weak and brittle. Osteoporosis is often known as the silent thief because bone losses occur without symptoms and progressive loss and thinning of bone tissue happens over many years. The aim of the study was to assess the effectiveness of Structured Teaching Programme on knowledge regarding prevention of Osteoporosis among premenopausal women (35-50 years) attending OPDs in a selected hospital, Raipur.
\end{abstract}

Objectives

- To assess the pretest level of knowledge regarding prevention of osteoporosis among premenopausal women in experimental group and control group.

- To determine the effectiveness of structured teaching programme on prevention of osteoporosis in experimental group.

- To find out the association between knowledge regarding prevention of osteoporosis and selected demographics variables of the premenopausal women.

Review of literature was prepared relevant to the study. The conceptual framework of the study was based on "Kenny's open system model. Pilot study was done among patients in general medicine OPD in a selected hospital, Raipur. The main study was conducted in Orthopedics and Obstetrics \& Gynecology OPDs in a selected hospital, Raipur. A total of 90 patients included in the study and they were selected using convenient sampling. The instrument used for data collection was structured knowledge questionnaire. Validity and reliability of the tool was done. Data was collected for the period of 4 weeks. Descriptive and inferential statistics were used to analyse the data.

It was observed in present study that majority (70\%) of the total sample in experimental and control group had inadequate level of knowledge regarding prevention of Osteoporosis. And it was observed that the mean post test score of experimental group with standard deviation was 19.98 \pm 3.02 which was apparentlyhigher than that of post test score of control group 14.11 \pm 4.74 . Statistical differences were computed and the independent $t$ value is 7.003 which was found significant at 0.05 . Hence, Structured Teaching Programme was effective on knowledge regarding prevention of Osteoporosis. The study findings also shows that the association between knowledge score and educational status $\left(x^{2}=9.511, \mathrm{P}=0.05\right)$, religion $\left(x^{2}=7.053, \mathrm{P}=0.05\right)$ and previous knowledge $\left(x^{2}=46.44, \mathrm{P}=0.05\right)$ were highly significant. Hence there was a significant association between pre-test knowledge and selected demographic variables of premenopausal women such as age, gender, education, income, religion, marital status, dietary pattern, age of menarche, age of marriage and previous knowledge.

Key Words: Structured Teaching Programme, Knowledge, Prevention of Osteoporosis, Premenopausal Women, Effectiveness. 


\section{INTRODUCTION}

Osteoporosis is one of the most common cause of fracture among postmenopausal women. According to International Osteoporosis Foundation, Osteoporosis cause more than 8.9 million fractures worldwide annually, resulting in an Osteoporosis fracture every 3 seconds. ${ }^{[3]}$ Osteoporosis is estimated to affect 200 million women worldwide, among these approximately $1 / 10^{\text {th }}$ of women aged 60 , $1 / 5^{\text {th }}$ of women aged $70,2 / 5^{\text {th }}$ of women aged 80 and $2 / 3^{\text {rd }}$ of women aged 90 years. ${ }^{[3]}$ In women over 45 yrs of age, Osteoporosis accounts for more days spent in hospital than many other diseases, including Diabetes, Myocardial Infarction and Cancer. It is projected that more than about $50 \%$ of all Osteoporosis hip fracture will occur in Asia by the year 2050. Osteoporosis is greatly under-diagnosed and undertreated in Asia, even in the most high risk patients who have already fractured. ${ }^{[3]}$ In India, at the end of 2000, there were estimated 9 million osteoporotic fractures of which 1.6 million women were affected with hip fracture, 1.7 million with forearm fractures and 1.4 million with vertebral fractures. In a study among India 30-60 yr women from low income groups, (bone mass index) at all the skeletal sites were much lower than values reported from developed countries, with a high prevalence of Osteopenia (52\%) and Osteoporosis (29\%) thought to be due to inadequate nutrition. ${ }^{[3]}$

Osteoporosis is often known as the silent thief because bone losses occur without symptoms and progressive loss and thinning of bone tissue happens over many years. This disease affects millions of people throughout the world. Women are four times more likely than men to develop this disease. In current situation, women give less attention to their health due to lack of time and other overload activities in their daily life. Most often, they rely on junk or processed food instead of regular balance a diet which has calcium, vitamin $\mathrm{D}$ and other minerals. Hence forth, the researchers felt the need to shed light regarding the prevention of Osteoporosis by providing adequate knowledge regarding the importance of good nutrition, following healthy life style and regular exercise which can increase the bone density which is a primary factor in prevention of Osteoporosis.

\section{Statement of problem}

A Quasi experimental study to assess the effectiveness of Structured Teaching Programme on knowledge regarding prevention of Osteoporosis among Premenopausal Women attending OPDs in a selected Hospital, Raipur.

\section{Objectives of the study}

1. To assess the pretest level of knowledge regarding prevention of Osteoporosis among premenopausal women in experimental group and control group.

2. To determine the effectiveness of structured teaching programme on prevention of Osteoporosis in experimental group.

3. To find out the association between knowledge regarding prevention of Osteoporosis and selected demographic variables of the premenopausal women.

\section{Null hypothesis}

$\mathrm{H}_{01}$-The mean post test knowledge of premenopausal women who received structured teaching Programme on the prevention of Osteoporosis will be significantly lower than the mean pretest knowledge.

$\mathrm{H}_{02}$ - The mean post test knowledge of premenopausal women who received STP on the prevention of Osteoporosis in the experimental group will be significantly lower than the mean post test knowledge of the control group.

$\mathrm{H}_{03^{-}}$There will be no significant association between level of knowledge regarding prevention of Osteoporosis and selected demographic variables. 


\section{Operational definition}

Structured Teaching Programme: -

In this study, it refers to a systematically planned, organized and executed teaching activity with specific objectives to impart knowledge regarding definition, causes, signs and symptoms and prevention of Osteoporosis among premenopausal women.

\section{Knowledge: -}

In this study, it refers to the ability to give correct response to the structured knowledge questionnaire asked by the investigator regarding prevention of Osteoporosis among premenopausal women.

Osteoporosis: - It refers to pathological condition of the bone characterized by decreased bone mass leading to an increased susceptibility to fracture.

\section{RESEARCH METHODOLOGY}

Research approach- Quantitative approach to identify the effectiveness of STP on knowledge regarding prevention of Osteoporosis among premenopausal women was used for this study.

Research design- Quasi-experimental pretest-posttest control group design was used for this study.

Research setting - The study was conducted in OPDs of a selected hospital, Raipur. The pilot study was conducted in General Medicine OPD and the main study conducted in Orthopedic OPD (for control group) and Gynecology OPD (for experimental group).

Sample size- 45 samples of premenopausal women in the age group of 35-50 years will be selected for experimental group and 45 samples in control group respectively.

Sampling technique - Convenient Sampling technique was used to select the samples who satisfy the sampling criteria from the selected setting.

\section{Data collection technique}

The study was conducted among 90 samples (45 samples from experimental group and 45 samples from control group).
The structured knowledge questionnaire was used to assess their knowledge regarding prevention of Osteoporosis and assess the effectiveness of structured teaching programme.

\section{Description of data collection instrument}

The tool consists of two sections:

Section 1- Demographic data including age, religion, education status, occupation, monthly income, dietary pattern, age of menarche, age at marriage and previous knowledge about Osteoporosis.

Section 2- Structured knowledge questionnaire to assess the knowledge and effectiveness of structured teaching program regarding prevention of Osteoporosis among premenopausal women. Structured knowledge questionnaire composed of 25 items to assess the knowledge regarding prevention of Osteoporosis.

The multiple choice question had four alternatives each with one right answer which was allotted a score of one and zero for every wrong answer has given after taking the pretest. Then post test is taken on $7^{\text {th }}$ day after providing Structured Teaching Program.

\section{Scoring}

The Multiple Choice Question has four alternatives each with right answer allotted a scoring of one and every wrong answer has given a score of zero. The total attainable score in knowledge questionnaire was 25. The total score will be converted into following ranges:

Level of knowledge score (\%)

Inadequate knowledge- $<50 \%$

\section{Moderately adequate- $\mathbf{5 1 - 7 5 \%}$}

Adequate knowledge- $>75-100 \%$

Testing of Tool - The content validity of the tool was obtained from seven experts for their opinion and suggestions. They validated the tool for adequacy of content, sequence and framing of question. Based on 
their suggestions, modification was made and the tool was finalized.

Validating - The content validity of the tool was established on the basis of opinion from experts in Nursing, Orthopedician, Gynecologist, Dietician. Language validation was done by Hindi expert and English expert.

Pre-testing- Pre-testing was done among premenopausal women attending OPD of a selected hospital, Raipur.

\section{Reliability}

The stability of the structured knowledge questionnaire on prevention of Osteoporosis was done by split half method. In order to establish reliability, the tool was administrated to 10 premenopausal women who satisfied sampling criteria. The reliability quotient obtained for the tool was 0.76 . Hence the tool was found reliable.

\section{Pilot study}

Pilot study was conducted with 10 samples (5 samples from experimental group and 5 samples from control group) from General medicine OPD of a selected hospital, Raipur.

\section{PROCEDURE FOR DATA COLLECTION}

After getting permission from Institute and Departments, the study was conducted among 90 samples (45 samples from experimental group and 45 samples from control group) by convenient sampling technique and based on inclusion and exclusion criteria (45 samples from experimental group was selected from Gynecological OPD and 45 samples from control group from orthopedic OPD). Informed and written consent was obtained from entire samples. The structured knowledge questionnaire was used to assess their knowledge regarding prevention of Osteoporosis and assess the effectiveness of structured teaching program.

\section{RESULTS SECTION-1}

\section{Pretest level of knowledge regarding prevention of Osteoporosis among premenopausal women in experimental group and control group}

Table 1: Level of knowledge in both experimental and control group $\mathrm{N}=90$ (45 experimental group +45 control group)

\begin{tabular}{|l|l|l|l|l|l|l|}
\hline Levels of Knowledge & \multicolumn{2}{|l|}{ Experimental Group } & \multicolumn{2}{|l|}{ Control group } & \multicolumn{2}{|l|}{ Total } \\
\hline & $\mathbf{F}$ & $\mathbf{\%}$ & $\mathbf{f}$ & $\mathbf{\%}$ & $\mathbf{f}$ & $\mathbf{\%}$ \\
\hline Inadequate & 34 & 75.55 & 29 & 64.44 & 63 & 70.00 \\
\hline Moderately Adequate & 8 & 17.77 & 12 & 26.66 & 20 & 22.22 \\
\hline Adequate & 3 & 6.66 & 4 & 8.88 & 7 & 7.77 \\
\hline
\end{tabular}

The data presented in table 1 shows that majority (70\%) of the total sample had inadequate level of knowledge regarding prevention of Osteoporosis. Similar trends were seen even after dividing the sample in the experimental and control group $(75.55 \%$ and $64.44 \%$ respectively).

Table- 2. Mean, standard deviation of pretest knowledge regarding prevention of Osteoporosis among premenopausal women in experimental group and control group.

\begin{tabular}{|l|l|l|l|l|l|l|l|}
\hline Group & Mean & Standard deviation & SEm & Mean Difference & 't' value & p-value df=88 & Significance \\
\cline { 1 - 8 } Experimental & 10.33 & 3.75 & 0.56 & 0.98 & 1.079 & 0.05 & Not significant \\
\cline { 1 - 3 } Control & 11.31 & 4.78 & 0.71 & & & & \\
\hline
\end{tabular}

The data presented in table 2 shows that the mean pre-test knowledge score in experimental and control group was $10.33,11.31$ respectively and obtained value of ' $\mathrm{t}$ ' for knowledge was 1.079 .
Hence, it is inferred that both groups did not differ significantly with regard to their knowledge before intervention. 
Solomon James Mangalaraj et.al. Effectiveness of structured teaching programme on knowledge regarding prevention of osteoporosis among premenopausal women.

\section{SECTION-2}

\section{Effectiveness of structured teaching programme on prevention of \\ Osteoporosis in experimental group}

$\mathbf{H}_{01}$ - The mean post test knowledge of premenopausal women who received structured teaching Programme on the prevention of Osteoporosis will be significantly lower than the mean pretest knowledge.

$\mathbf{H}_{02}$ - The mean post test knowledge of premenopausal women who received STP on the prevention of Osteoporosis in the experimental group will be significantly lower than the mean post test knowledge of the control group.

Table 3: Comparison of Pre-test and Post-test level of knowledge regarding prevention of Osteoporosis among premenopausal women in experimental group and control group. $\mathrm{N}=90(45+45)$

\begin{tabular}{|l|l|l|l|l|l|l|l|}
\hline Group & Test & Mean & Standard deviation & SEm & Df & Paired 't' value & Inference \\
\hline \multirow{2}{*}{ Experimentalgroup } & Pretest & 10.33 & 3.75 & 0.56 & 44 & $\begin{array}{l}\mathrm{t}=17.603 \\
\text { p value }=0.05\end{array}$ & 'S' \\
\cline { 2 - 8 } & Post test & 19.98 & 3.02 & 0.45 & & 'S' \\
\hline \multirow{2}{*}{ Controlgroup } & Pretest & 11.31 & 4.78 & 4.74 & 44 & $\begin{array}{l}\mathrm{t}=22.305 \\
\text { p value }=0.05\end{array}$ & \\
\cline { 2 - 5 } & Post test & 14.11 & 0.71 & 0.71 & & \\
\hline
\end{tabular}

$t=$ calculated value, $S=$ significant, NS=not significant

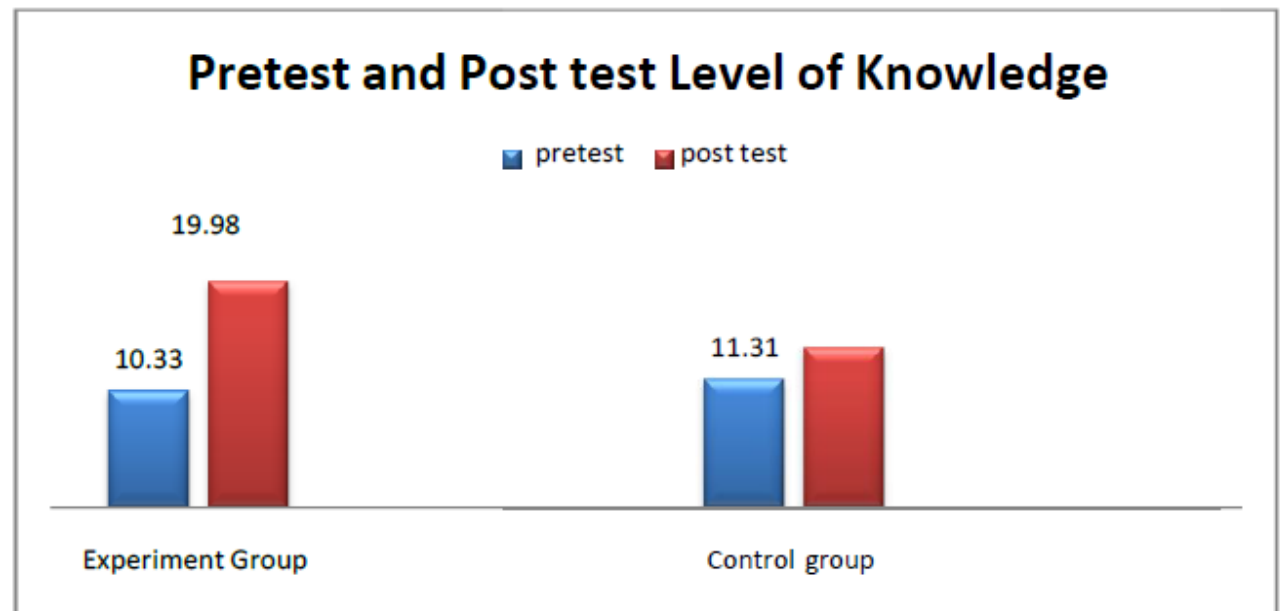

Figure-1 Comparison of Pre-test and Post-test level of knowledge regarding prevention of Osteoporosis among premenopausal women in experimental group and control group.

The data presented in table 3 shows that the mean post test score of experimental group with standard deviation was $19.98 \pm 3.02$ which was apparently much higher than that of mean pretest score of experimental group with standard deviation was 10.33 \pm 3.75 . The statistical significance of the differences was computed and the dependent $\mathrm{t}$ value is 17.603 which was found significant at 0.05 level.

Hence, the finding does not support the null hypothesis (H01) and the investigators reject the null hypothesis. This indicates that premenopausal women in experimental group have significantly gained the knowledge regarding prevention of Osteoporosis.

Table 4: Comparison of Post-test level of knowledge regarding prevention of Osteoporosis among premenopausal women in experimental group and control group. $\quad \mathrm{N}=90(45+45)$

\begin{tabular}{|l|l|l|l|l|l|l|l|l|}
\hline Group & Mean & Standard deviation & SEm & Mean difference & SEd & Unpaired t value & df & Inference \\
\hline Experimental & 19.98 & 3.02 & 0.45 & 5.87 & 0.838 & $\begin{array}{l}\text { t-value }=7.003 \\
\text { p value }=0.05\end{array}$ & 88 & 'S' \\
\hline Control & 14.11 & 4.74 & & 0.71 & & & \\
\hline
\end{tabular}

The data presented in table 4 shows that the mean post test score of experimental group with standard deviation was 19.98 \pm 3.02 which was apparently higher than that of post test score of control group 14.11 \pm 4.74 . Statistical differences was computed and the independent $t$ value is 7.003 which was found significant at 0.05 . 
Hence, the finding does not support the null hypothesis (H02) and the investigators rejects the null hypothesis. The mean post test knowledge of premenopausal women who received STP on the prevention of Osteoporosis in the experimental group will be significantly higher than the mean post test knowledge of the control group. This indicated that premenopausal women who received STP in experimental group have significantly gained the knowledge regarding prevention of Osteoporosis.

\section{SECTION - 3}

Find out the association between knowledge regarding prevention of Osteoporosis and selected demographic variables of the premenopausal women.

Ho3- There will be no significant association between level of knowledge regarding prevention of Osteoporosis and selected demographic variables.

The association between knowledge score and educational status $\left(x^{2}=9.511\right.$, $\mathrm{P}=0.05)$, religion $\left(x^{2}=7.053, \mathrm{P}=0.05\right)$ and previous knowledge $\left(x^{2}=46.44, \quad \mathrm{P}=0.05\right)$ where highly significant. However, the association between knowledge score and other demographic variables like age, occupation, monthly income, marital status, dietary pattern, bad habits, medication history and exposure to sunlight were not significant at 0.05 level.

It was observed that calculated chisquare value was more than the table value. Hence there was a significant association between pre-test knowledge and selected demographics variables of premenopausal women. Therefore, the investigators reject the null hypothesis.

\section{DISCUSSION}

1. The first objective of the study was to assess the pretest level of knowledge regarding prevention of Osteoporosis among premenopausal women in experimental group and control group.

It was observed in present study that majority (70\%) of the total sample had inadequate level of knowledge regarding prevention of Osteoporosis. Similar trends were seen even after dividing the sample in the experimental and control group (75.55\% and $64.44 \%$ respectively). The present study shows that the mean pre-test knowledge score in experimental and control group was 10.33, 11.31 respectively and obtained value of ' $t$ ' for knowledge was 1.079. Hence, it is inferred that both the group did not differ significantly with regard to their knowledge before intervention.

In another cross-sectional analytical study of 100 women above 45 years of upper class women chosen by simple random sampling which was conducted to assess Knowledge, attitude and preventive practice of women concerning Osteoporosis above 45 years women revealed that more than 75\% didn't know about Osteoporosis and $76 \%$ of women were not practicing preventive measures . ${ }^{[17]}$

\section{The second objective of the study was to determine the effectiveness of structured teaching Programme on prevention of Osteoporosis in experimental group}

The study findings shows that the mean post test score of experimental group with standard deviation was 19.98 \pm 3.02 which was apparently much higher than that of mean pretest score of experimental group with standard deviation was $10.33 \pm 3.75$. The statistical significance of the differences was computed and the dependent $\mathrm{t}$ value is 17.603 which was found significant at 0.05 level. Hence, the finding does not support the null hypothesis (H01) and the investigators reject the null hypothesis. This indicates that premenopausal women in experimental group have significantly gained knowledge regarding prevention ofOsteoporosis.

It was observed that the mean post test score of experimental group with standard deviation was $19.98 \pm 3.02$ which was apparently higher than that of post test score of control group 14.11 \pm 4.74 . Statistical differences were computed and 
the independent $t$ value is 7.003 which was found significant at 0.05 . Hence, the finding does not support the null hypothesis (H02) and the investigators reject the null hypothesis. The mean post test knowledge of premenopausal women who received STP on the prevention of Osteoporosis in the experimental group was significantly higher than the mean post test knowledge of the control group. This indicated that premenopausal women who received STP in experimental group have significantly gained knowledge regarding prevention of Osteoporosis.

In another quasi-experimental study which was conducted to assess the effectiveness of structured teaching programme on knowledge regarding risk factors and prevention of Osteoporosis among 50 premenopausal women in the age group of 30-45 years who were selected by convenient sampling technique revealed that the pre-test mean knowledge score was $6.72(\mathrm{SD}=2.7)$ and post-test mean knowledge score was $20.64(\mathrm{SD}=2.05)$ and paired ' $\mathrm{t}$ ' value was 28.819, which was not less than tabulated $t$ value at $(\mathrm{P}<0.05)$. Hence Structured Teaching Programme was effective in improving knowledge on risk factors and prevention of Osteoporosis. ${ }^{[25]}$

\section{The third objective is to find out the association between knowledge regarding prevention of Osteoporosis and selected demographic variables of the premenopausal women.}

The study findings shows that the association between knowledge score and educational status $\left(x^{2}=9.511, \quad \mathrm{p}=0.05\right)$, religion $\left(x^{2}=7.053, \mathrm{P}=0.05\right)$ and previous knowledge $\left(x^{2}=46.44, \mathrm{P}=0.05\right)$ were highly significant. However, the association between knowledge score and other demographic variables like age, occupation, monthly income, marital status, dietary pattern, bad habits, medication history and exposure to sunlight were not significant at 0.05 level. It was observed that calculated chi-square value was more than the table value. Hence there was a significant association between pre-test knowledge and selected demographics variables of premenopausal women. Therefore, the investigators reject the null hypothesis.

In another study, the association between pretest knowledge score and age $\left(x^{2}=10.74, \quad \mathrm{p}=0.005\right)$, educational status $\left(x^{2}=11.11, p=0.004\right)$, food habits $\left(x^{2}=8.56\right.$, $\mathrm{P}=0.014)$ and age of menopause $\left(x^{2}=9.89\right.$, $\mathrm{P}=0.02$ ) were highly significant. However, the association between knowledge score and other demographic variables like religion, nature of work and family income were not significant at 0.05 level. ${ }^{[23]}$

\section{CONCLUSION}

The focus of the study was to assess the effectiveness of Structured Teaching Programme on knowledge regarding prevention of Osteoporosis among Premenopausal Women (35-50 years) attending selected OPDs in a selected hospital, Raipur.

Quantitative research approach and quasi experimental research design was used for the study, conceptual framework of the study was based upon on J.W Kenny's Open System Model. The instrument used for data collection was a structured knowledge questionnaire which was prepared on the basis of review of literature and with the help of the subject experts, the content validity of tool was obtained from experts. Reliability of the tool was elicited by using split half method. The statistical analysis by Karl Pearson correlation coefficient was found to be 0.76 value which was correlated. Therefore, the instrument was found to be reliable.

A total of 90 samples (45 in experimental and 45 in control group) who met the inclusion criteria were selected by non-probability convenient sampling techniques. Written consent was obtained from the samples. Data was collected over a period of one month. Data collection was planned and gathered using structured knowledge questionnaire. The main study was conducted at Obstetrics and Gynecological and Orthopedic OPDs in a 
selected hospital, Raipur. Descriptive and inferential statistics were used for analysis and data were presented using tables and graph.

The mean post test knowledge of premenopausal women who received STP on the prevention of Osteoporosis in the experimental group was significantly higher than the mean post test knowledge of the control group. This indicated that premenopausal women who received STP in experimental group have significantly gained the knowledge regarding prevention of Osteoporosis. So, this study concludes that the structured teaching programme was effective in improving knowledge of premenopausal mother regarding prevention ofOsteoporosis.

\section{Implication}

The result of the study proves that the effectiveness of structured teaching program on knowledge of prevention of Osteoporosis among premenopausal women (35-50 years) attending selected OPDs in a selected hospital, Raipur had a significant effect in improving knowledge among premenopausal women.

The findings of the study have scope in the following area of nursing:

\section{Nursing Practice}

- The content of structured teaching programme will help the nursing personnel working in hospital and community for reinforcing their knowledge on prevention of Osteoporosis.

- The findings will help the nursing personnel to estimate the necessity to conduct health education programme for premenopausal women.

- The structured teaching programme can be used for making new plans and strategies which can be incorporated into nursing practice and helps in prevention and management of osteoporosis.

\section{Nursing Education}

- The nurse educators can use this structured teaching programme to teach the students about the prevention of Osteoporosis.

- To help the students to identify the needs for giving health education on prevention of Osteoporosis.

- The ability to clarify the doubts of premenopausal women and to educate them regarding prevention of Osteoporosis specially nursing students who are committed to further development of profession. Therefore the student nurse can use structured teaching programme on prevention of Osteoporosis to equip with adequate knowledge.

\section{Nursing Administration}

- Conduct in-service education programme on prevention of Osteoporosis.

- Helps the nurse administrator to apply various strategies to enhance the positive health of menopausal women.

- The people education service is an integral part of high quality, cost effective care. The nursing administration should see that the health promotion aspect is included in the nursing care.

\section{Nursing Research}

- Encourage further researcher to evaluate the factors influencing prevention of Osteoporosis among premenopausal women.

- Disseminate the finding through the conferences, seminars, publications in professional, international journals and World Wide Web.

- The findings of the study help to improve the knowledge regarding prevention and management of Osteoporosis.

\section{Limitations}

- The study sample was confined to only premenopausal women of 35-50 years. 
- The study sample was confined to only selected OPD'S of a selected hospital, Raipur.

- The study adopted convenient sampling, hence the generalization of the findings outside the sample size is limited.

- A structured knowledge questionnaire was used for data collection, which restricts the amount of information that could be obtained from the respondents.

- Recommendations

- A study to assess the practice of premenopausal women regarding prevention of osteoporosis can be conducted.

- Control could have been benefitted with knowledge regarding osteoporosis after post-test by using some educational aids.

- A comparative study may be conducted to assess the knowledge of osteoporosis among premenopausal women in different hospitals of Raipur.

\section{Acknowledgement: None}

\section{Conflict of Interest: None}

\section{Source of Funding: None}

\section{Ethical Approval: Approved}

\section{REFERENCES}

1. Lewis, Driksen , Heitkemper , Bucher. Lewis's Medical Surgical Nursing, Assessment and Management of Clinical Problems. Second South Asian Edition. Volume II. New Delhi: Reed Elsevier India Private limited; 2015: 1616-1618.

2. Osteoporosis Overview I NIH Osteoporosis and Related Bone Diseases Available at: http://www.bones.nih.gov>health-inf

3. Facts and statistics: International Foundation of Osteoporosis Available at: https://www.iofbonehealth.org/factsstatistics

4. In India ,1 out of 8 men and 1 out of 3 women suffer from osteoporosis: Study. Express news Services, 2012 Oct 21Available at: archive.indianexpress.com
5. Dr. Rajeev KS. Osteoporosis in Indian Women. Healthy Living -India times.2013 oct 18 Available at: https://m.indiatimes.com>healthyliving

6. Joyce.J. Filspalxie, (1983). Conceptual Model of Nursing, Analysis and Applications. Maryland.

7. Potter, Patrecia, (2005). Basic Nursing Theory and Practice (4th Ed.) USA: Mosby Publishers

8. Sharma S K. Nursing research and statistics. 2nd edition, New Delhi: Elsevier publishers limited 2015:10-200.

9. Anuradha Chakraborty, Moyna Chakravarty. Cross Sectional Study of Osteoporosis among Pre and Post Menopausal Women of Raipur City. Int J of Science and Research (IJSR) ISSN (Online): 2319-7064 Index Copernicus Value (2013): 6.14 | Impact Factor (2015): 6.391. January 2016:306-308. Available from:

https://www.researchgate.net/publication/31 9820970

10. Somibala Thokchom, Dr. Manju.A Study to Find out the Prevalence for Osteoporosis and Osteopenia in Pre and Post Menopausal Women in India: A Cross Sectional Study. International Journal of Science and Research (IJSR) ISSN (Online): 2319-7064 Index Copernicus Value (2013): 6.14 | Impact Factor (2014): 5.611 Volume 4 Issue 10, October 2015: 270-272. Available from: www.ijsr.net

11. Kadam NS, Chiplonkar SA, Khadilkar AV, Khadilkar VV. Prevalence of Osteoporosis in apparently healthy adults above 40 years of age in Pune City, India. Indian J Endocr Metab 2018; Volume 22, Issue 1. JanuaryFebruary 2018; 22:67-73. Available from: http://www.ijem.in/text.asp?2018/22/1/67/2 25003

12. Kadam N , Chiplonkars, et.al . Low bone mass in urban Indian women above 40 years of age: Prevelance and risk factors, Agharkar Research Institute, pune, India. 2010 Dec : 26(12):909-17. E pub 2010 Sep 17.

13. Priya A. Vasanthi, Sreekumary Radha, Bindu Nambisan. Prevalence and determinants of Osteoporosis in women aged 40-60 years. Vasanthi PA et al. Int J Reprod Contracept Obstet Gynecol. 2016 Dec;5(12):4434-4440.Available from: www.ijrcog.org 
14. Yakub Sanga "Prevalence of Osteoporosis in postmenopausal women and their risk factors in Indian prospects". IOSR Journal of Dental and Medical Sciences (IOSRJDMS), e-ISSN: 2279-0853, p-ISSN: 22790861. vol. 17, no. 5, 2018: 44- 46. Available from: www.iosrjournals.org

15. Jagiasi J, Bochare AM . The prevalence of Osteoporosis and osteopenia in persons attending a tertiary care hospital in Mumbai. International Journal of Orthopaedics Sciences 2018; 4(1): 656-658. Available from:

https://doi.org/10.22271/ortho.2018.v4.i1j.9 4

16. Latha P. Knowledge Regarding Osteoporosis among Women of Menopausal Age (45-65 Years) at Selected Village of Moga, Punjab. Narayana nursing journal. pp-39-41.

17. Agrawal J. Knowledge, attitude and preventive practice of women concerning Osteoporosis above 45 years women. Int $\mathbf{J}$ Reprod Contracept Obstet Gynecol. 2018Sep;7(9):3863-3867.

Availablefrom:http://dx.doi.org/10.18203/2 320-1770.ijrcog20183809

18. Yamini Rathod 'et al'. A Descriptive Study on Knowledge Regarding Prevention of Osteoporosis among Pre-Menopausal Women in Rural Areas of Waghodia Taluka with a View to Develop Information Booklet. International Journal of Advance Research and Development. Volume2, Issue11.pp- 17-32. Available from:www.ijarnd.com

19. McLendon AN, Woodis CB. A Review of Osteoporosis Management in Younger Premenopausal Women. Volume: 10 issue: 1, page(s): 59-77. Article first published online: January 1, 2014; Issue published: January 1, 2014 . Available from: https://doi.org/10.2217/WHE.13.73

20. Giangregorio L, Thabane L, Et.al. Osteoporosis knowledge among individuals with recent fragility fracture. Department of kinesiology, University of waterloo, Canada. 2010 Mar-Apr; 29(2): 99-107.

21. Takoo S. A Study to Assess the Effectiveness of Structured Teaching
Program on Knowledge of Menopausal Women regarding Prevention and Management of Osteoporosis, Attending Gynaecological OPD of Batra Hospital and Medical Research Centre, New Delhi. International Journal of Nursing \& Midwifery Research. Volume 5, Issue 1 2018:12-17

22. Kulal R, Handa S. Negi R. Effectiveness of structured teaching programme on knowledge regarding Osteoporosis and its management among menopausal women. International journal of trend in scientific research and development (IJTSRD). Volume 1 issue 6 Sep-oct 2017: 448-459

23. Chopade SS, Jawadagi S, Sikandar BAJ. A study to assess the effectiveness of planned teaching programme on knowledge of Type I Osteoporosis and its prevention among menopause women in selected PHC at Bijapur. IOSR Journal of Nursing and Health Science (IOSR-JNHS) e-ISSN: 2320-1959.p- ISSN: 2320-1940 Volume 3, Issue 6 Ver. II (Nov.-Dec. 2014), PP 21-25 www.iosrjournals.org

24. Mary JJ et al. Effect of STP on knowledge, attitude and practice of menopausal women regarding the prevention of cardiac disease and Osteoporosis in Selected Health Centers of Kannur District, Kerala. Nurse Health Care Int J 2017,1(5):000130

25. Dhanalakshmi J, Malathi.S. Effectiveness of structured teaching programme on knowledge regarding risk factors and prevention of Osteoporosis among premenopausal women. Int. J. of Allied Med. Sci. and Cli. Research Vol-6(3)2018: 650-653. Available from: www.ijamscr.com

26. Jayabharathi B. Knowledge of menopause among menopausal women.NNT;7(12) March 2012: page 14.

How to cite this article: Mangalaraj SJ, Yadav S, Rathi $\mathrm{S}$ et.al. Effectiveness of structured teaching programme on knowledge regarding prevention of osteoporosis among premenopausal women. Int J Health Sci Res. 2021; 11(11): 265-274. DOI: https://doi.org/10. 52403/ijhsr.20211132 